\title{
The genesis of andesite magma inferred from major and trace element compositions of amphibole
}

\author{
I. OKADA ${ }^{1 *}$, T. SHIBATA ${ }^{1}$, M. YOSHIKAWA ${ }^{1}$,
} T. SUGIMOTO ${ }^{2}$, AND Y. HAYASAKA ${ }^{1}$

${ }^{1}$ Hiroshima University. 1-3-1 Kagamiyama, HigashiHiroshima, Hiroshima, 739-8526, Japan

(*Correspondence : ikuo-okada@hiroshima-u.ac.jp)

${ }^{2}$ Geothermal Engineering Co., Ltd. 356-6 Ogamaoshimizu, Takizawa, Iwate, 020-0758, Japan

The andesite magma is prominent in a subduction zone, and is generally produced through a complex magma process. This hybrid feature makes it difficult to understand the genesis of the andesite magma based on the bulk chemical and isotopic compositions. Instead, mineral phases in the magma preserve the geochemical information of surrounding equilibrium melt during the crystallization. Recently, crystallized pressure $(\mathrm{P})$, tempearture $(\mathrm{T})$ and major element compositions of the equilibrium melt with amphiboles have been able to calculate only from major element contents of amphiboles [e.g., 1, 2]. Furthremore, partition coefficients of trace elements between amphibole and melt, which are quite sensitive $\mathrm{T}$ and $\mathrm{SiO}_{2}$ contents of melt, are determined with various physicochemical conditions [3]. Therefore, we analysed major and trace element compositions of amphiboles in andesite from the Quaternary Yufu volcano, Kyushu, Japan by EPMA and LA-ICP-MS and estimated the P-T conditions, major and trace element compositions of equilibrium melt with amphiboles to discuss the magma genesis. From the results of estimated P-T conditions and $\mathrm{SiO}_{2}$ contents of the melt, the amphiboles can be devided into Groups I (327-624 MPa, 900-1016 ${ }^{\circ} \mathrm{C}$ and 52.3-65.6 wt.\%) and II (80-229 $\mathrm{MPa}, 776-865^{\circ} \mathrm{C}$ and $71.4-79.0$ wt.\%). The primitive mantle-normalized multi-element diagram of the estimated melts in equilibrium with Group I show enrichment of large ion lithophile element (LILE) and depletion of $\mathrm{Nb}$ whereas negative $\mathrm{Sr}$ and $\mathrm{Zr}$ spikes and depleted in LILE are obsereved from Group II. In addition, $\mathrm{Sr} / \mathrm{Y}$ ratios of Group I melt are 59-133, similar to those of Daisen volcano, which are thought to be generated by partial melting of the subducted slab [4]. On the other hand, the low Sr/Y ratios (817) are found from the Group II melt. Together with the other characteristics of the trace element, crustal materials might contribute to the genesis of the melt of the Group II.

[1] Putirka (2016) Am Mineral, 101, 841. [2] Ridolfi \& Renzulii (2012) CMP, $163: 877-895$. [3] Nandedkar et al. (2016) CMP, 171 : 71. [4] Kimura et al. (2005) The Island Arc , 14, 115-136. 